\title{
Sudden Bilateral Sensorineural Hearing Loss as an Unusual Consequence of Accidental Ingestion of Potassium Hydroxide
}

\author{
A. Ciorba ${ }^{a}$ R. Bovo ${ }^{a}$ A. Castiglione ${ }^{a}$ A. Pirodda ${ }^{b}$ A. Martini ${ }^{a}$

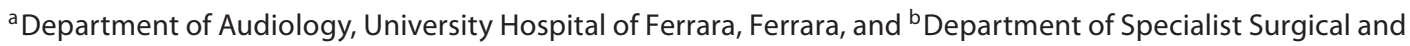 \\ Anesthesiological Sciences, University of Bologna, Bologna, Italy
}

\section{Key Words}

Sudden sensorineural hearing loss • Potassium hydroxide • Caustic ingestion

\begin{abstract}
Objective: To discuss the possible etiopathogenetic mechanism of inner ear damage induced by the ingestion of potassium hydroxide $(\mathrm{KOH})$. Clinical Presentation and Intervention: We report the case of a 37-year-old patient with sudden bilateral sensorineural hearing loss after accidental ingestion of a $\mathrm{KOH}$ solution. The first ear, nose and throat examination disclosed only mild edema of the upper airways. He was treated in the intensive care unit and prescribed highdose steroids, proton pump inhibitors and sucralfate for 2 weeks. Unfortunately, there was no recovery of the hearing loss, and no audiogram changes were noticed after 12 months of follow-up. Conclusion: After exploring the possible etiopathogenetic mechanism involved, the authors believe that in this case, a transient severe hemodynamic imbalance can actually be considered to be the most reliable explanation for the inner ear damage and subsequent onset of permanent bilateral sensorineural hearing loss.
\end{abstract}

Copyright $\odot 2010$ S. Karger AG, Base

\section{Introduction}

Approximately 5,000-10,000 cases of caustic ingestion occur in the US every year. Of those, approximately 50 $80 \%$ occur in the pediatric population, with a reported male:female ratio of $2: 1[1,2]$. The most commonly ingested agents are generally those that are used for cleaning. Potassium hydroxide $(\mathrm{KOH})$ is the basic ingredient of most soft and liquid soaps. It is defined as a 'strong base' of industrial application.

The ingestion of caustic substances induces a wide range of well-characterized injuries to the gastrointestinal tract, ranging from mild to severe, that potentially can lead to chronic disease. Caustic ingestion in children is usually accidental, whereas ingestion by adults is more often due to suicidal intent [3].

Caustic agents with a $\mathrm{pH}$ level $<2$ or $>12$ rapidly penetrate the mucosal layers of the gastrointestinal tract, resulting in necrosis-induced eschar formation in the mucosa, which limits deep tissue penetration. The extent of tissue destruction depends on the physical form, type, and concentration of the corrosive agent, premorbid state of the tissue, contact duration, and amount of substance ingested.

Esophagogastroduodenoscopy is considered to be the gold standard for safely assessing the gastrointestinal extent of caustic ingestion injuries, as well as classifying the mucosal lesions (Zargar system, table 1) [3]. Major complications reported after caustic ingestions are systemic

Prof. Alessandro Martin

Audiology Department, University Hospital of Ferrara

C.so Giovecca 203

IT-44100 Ferrara (Italy)

Tel. +39 0532237 451, Fax +39 0532236 887, E-Mail alessandro.martini@ unife.it 
(aspiration pneumonia, respiratory, hepatic and renal failure) and gastrointestinal (stricture, bleeding, perforation and fistula) [3]. Unusual complications reported include pancreatitis and duodenal and colonic necrosis $[4,5]$. To date, in the literature, sensorineural hearing loss has not been previously reported as a consequence of caustic ingestion. To our knowledge, $\mathrm{KOH}$ has not been shown to be an ototoxic drug, and this is the first case of sudden bilateral sensorineural hearing loss following caustic $\mathrm{KOH}$ ingestion.

\section{Case Report}

A 37-year-old patient presented with sudden bilateral sensorineural hearing loss following accidental ingestion of a $\mathrm{KOH}$ solution. Immediately after the ingestion, the patient developed dysphagia, odynophagia and nausea; he was promptly transferred to the emergency room. The patient also complained of bilateral hearing loss (fig. 1) with tinnitus, but no vestibular signs or symptoms. The patient did not have any history of hearing loss or tinnitus before the accident and had always worked as an office employee with no professional or leisure exposure to high noise.

Assessment of the upper airways using videoendoscopy revealed edema and hyperemia of the oral cavity and the pharynx mucosa and signs of mucosal dysepithelization. There was no adenoid tissue in the rhinopharynx, but in the larynx the arithenoids appeared hyperemic and edematous. There was mild epiglottic edema, but no glottic lesion was present. Otoscopy was normal. At esophagogastroduodenoscopy evaluation, the esophagus appeared regularly canalized, but signs of mucosal dysepithelization and erosion were noticed, especially in the cervical tract (grade 1 and 2a lesions according to Zargar's classification, table 2). Laboratory data at admission showed slight anemia ( $\mathrm{Hb}$ $10.7 \mathrm{~g} / \mathrm{dl}$ ), hypernatremia ( $\mathrm{Na} 152 \mathrm{mEq} / \mathrm{l})$, mild inflammatory reaction (WBC 4,250/ $\mathrm{mm}^{3}$ ) and slight renal failure (serum creatinine $2.6 \mathrm{mg} / \mathrm{dl}$; reference range $0.5-1.4$ ).

The patient was transferred to the intensive care unit for constant monitoring of respiratory function. An audiogram showed bilateral sensorineural hearing loss for the high frequencies of a moderate grade (fig. 1). Tympanogram was bilaterally normal (type A) and stapedial reflexes were bilaterally present. Auditory brainstem responses were normal, excluding the presence of retrocochlear lesions. The patient was treated with high-dose steroids, proton pump inhibitors and sucralfate for 2 weeks. At follow-up, endoscopic assessment of the upper respiratory and digestive tract showed a progressive improvement of the mucosal lesions with complete healing after 1 month. Unfortunately, after 12 months of follow-up, no changes in the audiogram were noticed.

\section{Discussion}

Among a number of etiopathogenetic mechanisms involved in this case, $\mathrm{KOH}$ vapors could have penetrated the middle ear cavity through the Eustachian tube without

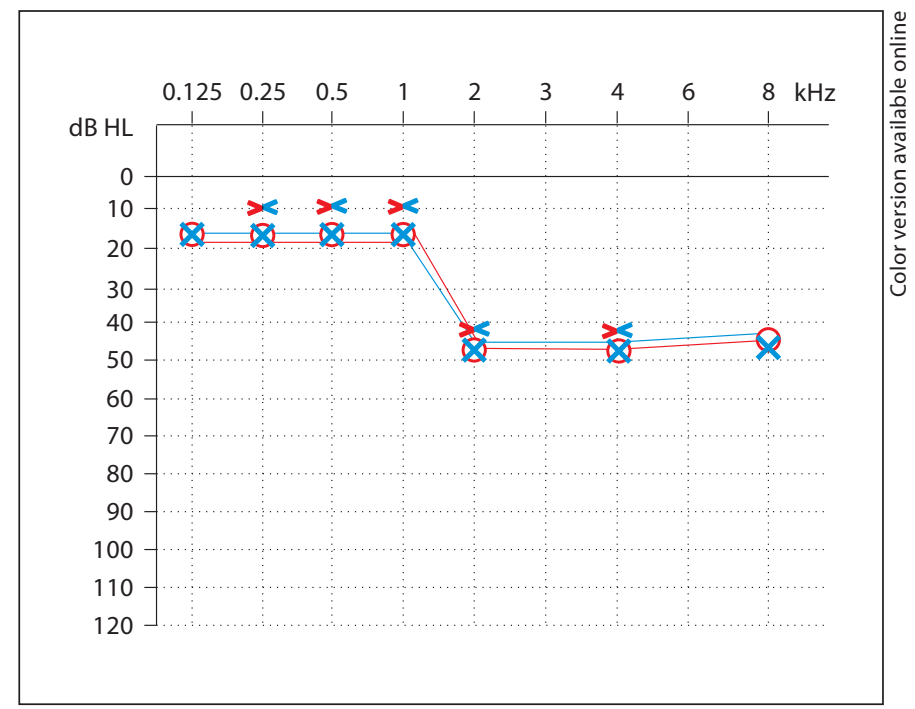

Fig. 1. Audiogram showing bilateral sensorineural hearing loss for high frequencies of moderate grade.

Table 1. Zargar's grading classification of mucosal injury caused by ingestion of caustic substances

\begin{tabular}{ll} 
Grade 0 & normal mucosa \\
\hline Grade 1 & edema and hypermia of the mucosa \\
\hline Grade 2a & $\begin{array}{l}\text { superficial ulceration, erosions, friability, blisters, } \\
\text { exudates, hemorrhages, whitish membranes }\end{array}$ \\
\hline Grade 2b & $\begin{array}{l}\text { grade 2a plus deep discrete or circumferential } \\
\text { ulcerations }\end{array}$ \\
\hline Grade 3a & $\begin{array}{l}\text { small scattered areas of multiple ulceration and areas } \\
\text { of necrosis with brown-black or greyish discoloration }\end{array}$ \\
\hline Grade 3b & extensive necrosis
\end{tabular}

Table 2. Major reported complications after caustic ingestion (modified from Cheng et al. [3])

Systemic complications

Aspiration pneumonia

Respiratory failure

Hepatic failure

Renal failure

Gastrointestinal complications

Stricture

Bleeding

Perforation

Fistula 
provoking any damage along the way. The Eustachian tube physiologically allows a free gas exchange between the middle ear and the nasopharynx, quantified by Sadé and $\operatorname{Ar}[6]$ to be at least 1 or $2 \mu l$ during swallowing, thereby providing a small quantity of caustic vapors, possibly not sufficient to jeopardize the mucous membrane, thus arriving at the middle ear, which could diffuse in the perilymph fluids through the round window membrane to the organ of Corti. An alteration of the delicate acid-base balance, which is essential for the homeostasis of the inner ear, is sufficient to threaten it. Therefore, the penetration of a strong base such as $\mathrm{KOH}$ in the closed system of the membranous labyrinth could possibly result in damage to the sensory epithelium. Direct, isolated damage to the inner ear seems unlikely without any tubal or tympanic lesion, as it is known that tissue edema occurs immediately, while over time necrotic tissue replaces the cells [7]. These severe cellular injuries occur rapidly after alkaline ingestion, within minutes from the contact and even for small quantities or low concentration of alkaline solutions [7], thus making it difficult to support a hypothesis of such a sectorial sufferance. However, a change in middle ear pressure, which is reported to be able to influence the function of the inner ear [8], seems improbable to coexist with unaffected tubal function; for the same reason, functional anomalies of the tensor tympani, although credited as having some possible adverse effect on the labyrinth [9], and considered in the hypthesized link between labyrinthine disorders and gastroesophageal reflux [10], might have a hypothetic marginal role. Finally, the most probable explanation could be an indirect, systemic effect casually involving the inner ear as a sensory organ with a blood supply of terminal type. This involves a reflex mechanism that depends on vagal activation through the transmission of pathological stimuli from vagal afferents to the brainstem, as reported concerning the stomach [11]. This reflex mechanism causes a sequence of hemodynamic changes that can affect the inner ear circulation [12] through a abrupt fall of the systemic blood pressure followed by an altered autonomic response. The vagal activation, causing a sharp hypotension, is subsequently followed by an exaggerated vasoconstriction that results in a transient lack of perfusion to the inner ear. This etiopathogenic model [11, 12] suggests an opportunity for a multidisciplinary approach to inner ear dysfunction of uncertain origin and could explain a number of cases which would otherwise be classified as 'idiopathic'. The occurrence of such a kind of phenomenon in the reported case could actually be justified from both physical and psychogenic stimuli.

\section{Conclusion}

We believe that a transient, severe hemodynamic imbalance can actually be considered to be the most plausible explanation for the onset of the sudden bilateral inner ear sufferance in the case presented. Experimental studies could be useful to elucidate the etiopathogenetical mechanism(s) of this type of damage to the inner ear epithelium.

\section{References}

- 1 Arévalo-Silva C, Eliashar R, Wohlgelernter J, Elidan J, Gross M: Ingestion of caustic substances: a 15-year experience. Laryngoscope 2006;116:1422-1426.

2 Friedman EM: Caustic ingestion and foreign bodies in the aerodigestive tract; in Bailey BJ (ed): Head and Neck Surgery - Otolaryngology, ed 3. Philadelphia, Lippincott, 2001, pp 925-932.

>3 Cheng HT, Cheng CL, Lin CH, Tang JH, Chu YY, Liu NJ, Chen PC: Caustic ingestion in adults: the role of endoscopic classification in predicting outcome. BMC Gastroenterol 2008;8:31.

4 Nijhawan S, Jain P: Acute pancreatitis as an unusual complication of corrosive ingestion. J Gastrointest Liver Dis 2007;16:345-346.

$\checkmark 5$ Guth AA, Pachter HL, Albanese C, Kim U: Combined duodenal and colonic necrosis: an unusual sequela of caustic ingestion. J Clin Gastroenterol 1994;19:303-305.

\footnotetext{
6 Sadé J, Ar A: Middle ear and auditory tube: middle ear clearance, gas exchange, and pressure regulation. Otolaryngol Head Neck Surg 1997;116:499-524.

-7 García Díaz E, Castro Fernández M, Romero Gómez M, Castilla Higuero L: Upper gastrointestinal tract injury caused by ingestion of caustic substances. Gastroenterol Hepatol 2001;24:191-195.

8 Goldstein B, Shulman A, Avitable MJ: Clear tinnitus, middle-ear pressure, and tinnitus relief: a prospective trial. Int Tinnitus J 2007; 13:29-39.

9 Pau HW, Punke C, Zehlicke T, Dressler D, Sievert U: Tonic contractions of the tensor tympani muscle: a key to some non-specific middle ear symptoms? Hypothesis and data from temporal bone experiments. Acta Otolaryngol 2005;125:1168-1175.
}

10 Pirodda A, Brandolini C, Raimondi MC, Modugno GC: The possible role of proton pump inhibitors on the homeostasis of the inner ear. Med Hypotheses 2009;72:325326.

11 Lugon JR, Moreira MD, de Almeida JM, Silva AS, Esberard EC, Bousquet-Santos K, Carvalho AG, Mendes LC, da Nobrega AC: Cardiovascular autonomic response to food ingestion in patients with gastritis: a comparison between Helicobacter pylori-positive and -negative patients. Helicobacter 2006;11:173-180.

12 Pirodda A, Ferri GG, Modugno GC, Borghi C: Systemic hypotension and the development of acute sensorineural hearing loss in young healthy subjects. Acta Otolaryngol Head Neck Surg 2001;127:1049-1152. 